\section{More Than Wargaming: Exploring the Miniaturing Pastime}

\author{
Mikko Meriläinen' ${ }^{\mathbb{D}}$, Jaakko Stenros', \\ and Katriina Heljakka ${ }^{2}$
}

Simulation \& Gaming

$1-17$

(C) The Author(s) 2020

(c) (i)

Article reuse guidelines: sagepub.com/journals-permissions DOI: I0.| | 77// 046878|20929052 journals.sagepub.com/home/sag

(9SAGE

\title{
Abstract
}

Background. Miniaturing, or painting, collecting, and gaming with miniature wargaming figurines, is a popular, yet vastly underresearched subject. Previous research suggests a multitude of practices and ways of engaging with miniatures.

Aim. This qualitative study explores the various elements of miniaturing to both map the phenomenon and build a foundation for further research.

Method. Miniaturing is explored through a thematic analysis of I 27 open-ended survey responses by adult Finnish miniature enthusiasts.

Results. Responses suggest a dual core to miniaturing, consisting of crafting and gaming. In addition to these core activities, storytelling, collecting, socializing and displaying and appreciating appear commonly, with considerable individual variation. The different elements are closely intertwined, based on individual preferences and resources.

Discussion. As a pastime, miniaturing occupies an interesting position with elements of crafting, toy play and gaming, and escapes easy situating. The considerable individual variation in enthusiasts' preferences suggests a multitude of fruitful approaches in further research.

\section{Keywords}

crafting, miniaturing, role-playing, toy play, wargaming, Warhammer

\footnotetext{
'Tampere University, Finland

${ }^{2}$ University of Turku, Finland

Corresponding Author:

Mikko Meriläinen, Tampere University, Kanslerinrinne I, 330I4 Tampere, Finland.

Email: mikko.merilainen@tuni.fi
} 


\section{Introduction}

Miniature wargaming is a pastime with a long history stretching back centuries. Emerging from CHESS, wargaming was not only a recreational pursuit, but a way to simulate battles and train military officers. While the history of miniature wargaming has been covered in existing research (e.g. Lewin, 2012; Peterson, 2012), current play practices and the culture around them have received scarce attention in academia. The contemporary miniature pastime is intimately influenced by the role-playing game boom of the mid-to-late 1970 s and early 1980s. The first commercial role-playing game product, DUNGEONS \& DRAGONS (1974), emerged from the wargaming tradition, and the first edition of the definitive miniature wargame WARHAMMER was labeled a "Mass Combat Fantasy Role-Playing Game". However, over the years these two traditions have again diverged and today they are two very distinct pastimes, albeit with often considerable overlap as shown by our results.

Since its inception in the 1980 s, the contemporary miniature industry and the associated pastime have grown immensely. Games Workshop, the world's largest miniature game producer, is a publicly traded company with sales of $£ 256.6$ million in 2019 (Games Workshop, 2019) and there are countless thriving global and local communities for miniature enthusiasts. Despite this, there is scarce research on miniatures and people who collect, game, and play with them. While academic interest in games has exploded since the turn of the Millennium, miniature wargamers have been almost ignored while neighbouring areas of digital games, role-playing games, board games, and learning simulation have garnered attention. The research conducted by Bernard Cova, Stefano Pace, and David J. Park (2007) as well as Marcus Carter, Martin Gibbs, and Mitchell Harrop (Carter, Gibbs, \& Harrop, 2014; Carter, Harrop, \& Gibbs, 2014; Harrop et al., 2013) on the WARHAMMER miniature games and their players, comprise a significant portion of the academic literature on the modern miniature pastime. Another important contribution is Ville Kankainen's (2016) exploration of the physical and digital versions of the miniature board game BLOOD BOWL.

Earlier research suggests that while gaming is often a prominent part of the miniature pastime, there are many other ways to engage with miniatures. Rather than being a single, clearly delineated hobby, the miniature pastime appears to be a collection of diverse interlinked activities (Carter, Gibbs, \& Harrop, 2014; Kankainen, 2016). In this study we examine how Finnish enthusiasts engage with miniatures. We call this collection of hobbyist practices miniaturing. Through a thematic analysis of qualitative survey data $(\mathrm{N}=127)$ consisting of open-ended questions we identify different aspects of miniature pastime culture to chart this largely unexplored phenomenon.

\section{Background}

The roots of miniature wargaming are long and deep, and the genre has numerous important turning points. The origins of wargames lie in 17th and 18th century variants of CHESS, which were elaborated on and rendered more "realistic" by numerous designers - often with the aim to simulate battle and to teach military strategy and 
thinking. A key turning-point in breaking away from CHESS, and towards establishing KRIEGSSPIEL, was scholar of natural sciences and mathematics Johann C. L. Hellwig (1743-1831), whose 1780 ruleset created the foundation for wargaming (e.g. movement, displacement, victory conditions, concrete setting, terrain). During the 19th century, KRIEGSSPIEL became quite popular in Prussia and the rest of German speaking Europe, especially among military men. Georg Leopold von Reiswitz (1760 1828) and later his son Georg H. R. J. von Reiswitz (1794-1827) are key figures in this development. They introduced KRIEGSSPIEL to King Wilhelm III and developed the gaming implements and rules by, for example, introducing the umpire and unit hitpoints. It was the younger Reiswitz's version of the game that was adopted as a training tool in the Preussian army (Murray, 1952; Peterson, 2012).

Representative figurines, tin soldiers, were married to wargaming in Britain in the late 19th century. Previously accurately-scaled blocks had stood in for troops. The turning-point for wargaming in the English-speaking world was science fiction author H.G. Wells' (1866-1946) wargaming rule-book LITTLE WARS (1913). Some contemporary designers consider LITTLE WARS as the starting point of miniature wargaming, since Wells' rules give primacy to figurines and terrain (Pirinen, personal communication, 2019). Wells was also a pacifist, interested in wargaming as a hobby, not as training. During the 20th century miniature wargaming developed especially in the United States in devoted hobby communities. These communities cross pollinated with board game communities, military simulations, and therapeutic psychodramas leading to the development of DUNGEONS \& DRAGONS in 1974 by Gary Gygax (1938-2008) and Dave Arneson (1947-2009) (Peterson, 2012, 2018).

DUNGEONS \& DRAGONS developed from the wargaming tradition, but it became the first commodified role-playing game. It had an important influence on the miniature wargaming tradition as well, since it brought in the fantasy settings. There has always been a tension between realism and playability in wargames, between accurate simulation of combat situations and the recreational flow of the wargaming experience (see Schuurman, 2017). Bringing in fantastic settings, characters, and equipment is only the latest extension of that. However, there is still a tension in the hobby communities between realistic simulations and fantastic recreation. The idea of creating a serial game or a continuous campaign also became important at this time for commercial reasons. It was not enough to buy just the rule set, but also ever more complex additions to the lore and rules (Dunnigan, 2005). In a similar vein, new miniatures, rules and lore were introduced in hobby magazines such as Games Workshop's White Dwarf.

The most successful, and most important to our survey responders, contemporary miniature wargame is WARHAMMER, originally published as WARHAMMER: THE MASS COMBAT FANTASY ROLE-PLAYING GAME (commonly referred to as WARHAMMER FANTASY BATTLE or simply as WARHAMMER FANTASY) in 1983 and written by Bryan Ansell, Richard Halliwell, and Rick Priestley. This fantasy game, and its science fiction sibling, WARHAMMER 40,000 (originally published as WARHAMMER 40,000 ROGUE TRADER in 1987, designed by Rick Priestley), have been the definitive fantasy miniature wargames for decades. Games Workshop, 
the company behind WARHAMMER, has been actively creating and fostering a hobby around miniature wargaming: building and painting figurines for gaming and displaying, creating dioramas, competing in tournaments, as well as creating expansive fictional settings detailed in source books, novels, digital games, and comics. The company magazine, White Dwarf (since 1977), has been an important part of this, as have their chain of stores and events. In addition to the core Warhammer titles, Games Workshop has published a wide range of other miniature games and miniature board games, such as LORD OF THE RINGS (2001), MORDHEIM (1999), BLOOD BOWL (first edition 1986), SPACE HULK (first edition 1989), and the current rebooted version of WARHAMMER FANTASY, WARHAMMER AGE OF SIGMAR (2015). With the exception of LORD OF THE RINGS, these games usually expand the setting of one of the core WARHAMMER games, BLOOD BOWL for example being a game akin to rugby or American football set in the fantasy world of WARHAMMER.

Games Workshop is obviously not the only company in the miniature gaming market, but with its games, magazines, figurines, and a large established fanbase, it is the largest and most visible. A multitude of miniature gaming companies exists, as do companies that create miniatures without a specific target game system. Furthermore, historical miniature gaming has not disappeared either, but has a strong following, with titles such as SAGA (2011) and BOLT ACTION (2012) popular among players and modern plastic tooling enabling hobbyists to build large armies with ease.

While wargaming is a prominent part of the miniature pastime, it does not encompass it. Miniatures are also bought for purposes other than wargaming, such as painting, modelling, and collecting without intention to use the miniatures for gaming or playing. As per their history, miniatures are a common feature of the role-playing game hobby, where they are used as both playing pieces to visualize combat and as physical representations of imaginary characters. Several miniature companies specifically cater to these non-wargaming purposes, for example by explicitly making miniatures for role-playing game characters and by releasing limited edition miniatures for collectors and miniature busts for painters.

\section{The Finnish Context}

Leading up to this study we were unable to find any existing research on Finnish miniature wargaming or miniaturing as a hobby, not even popular histories. However, based on our data, exhibitions in museums featuring disconnected objects of (miniature) wargaming (e.g. Clerc, 2018; Kunttu, 2018; Suomen pelimuseo, n.d.), online hobby forums, personal communications with industry professionals as well as personal experience we can broadly outline the Finnish context on miniaturing.

What we view as contemporary miniaturing mostly started to emerge in Finland during the mid-to-late 1980s when bookstores and later specialty role-playing game stores started selling fantasy figurines and game rules. Miniaturing and role-playing games were closely connected during this so-called first wave of Finnish miniaturing. Of note during this time are also the board games HEROQUEST and SPACE CRUSADE. Both were produced by board game company Milton Bradley, featured plastic 
miniatures and were made in collaboration with Games Workshop. Finnish language editions of these two games were produced in 1990 and marketed to a wide audience, and our data suggests that they served as an entry point for many miniature enthusiasts. Based on our data, a second wave of Finnish miniaturing came about in the earlyto-mid 1990s, with the releases of the 4th (1992) and 5th (1996) editions of WARHAMMER FANTASY BATTLE and the 2nd (1993) edition of WARHAMMER 40,000 . All of these games came in boxed sets with enough plastic miniatures to start gaming out of the box. The vast majority of our respondents had started their miniaturing in one of these two waves. It should be noted, however, that the two waves outlined above primarily deal with fantasy and science fiction miniature gaming, in effect focusing on Games Workshop titles.

As an interesting side note, there is a tradition of miniature wargaming in the Finnish military, combining influences from the German Kriegsspiel tradition and from Russian wargaming. Later influences have also come from the United Kingdom and the United States. Some of these simulations used figurines and terrain, others used maps and tokens. This tradition was strongest before the Second World War, although recently military interest in non-digital simulation has increased. Recreational miniature gaming has also existed, but information on this is even more scarce. The Finnish Museum of Games features Reijo Paulus' SOTAPELI (Eng. Wargame), which is a homegrown system with intricate painted figurines carved from wood. It is currently not known how these traditions - and maybe others as well - have influenced each other over the years in Finland.

Today Finland, a nation of 5.5 million inhabitants, has a vibrant, if small community of miniature wargamers and other miniaturing enthusiasts. Miniatures feature prominently in Finland's biggest annual role-playing game convention Ropecon, with painting contests, wargaming tournaments and painting workshops. Miniatures are sold by most stores that stock tabletop gaming supplies and there is a dedicated Games Workshop store in Helsinki. There is also a thriving online community with several active Finnishspeaking Facebook groups as well as the online forum Sotavasara.net (Eng. Warhammer. net). It is difficult to estimate how many miniature wargamers there are in Finland, but based on the Finnish Player Barometer data from 2018 (Kinnunen et al., 2018), approximately $2 \%$ of the $10-75$ year olds in Finland play miniature wargames at least occasionally, and $0.5 \%$ play regularly. This would mean a population of approximately 88,000 people who have at least tried miniature wargaming at some point with a possible population of 22,000 active players in Finland, although we feel these numbers very probably overestimate the number of players due to selection bias in the barometer.

Men and boys play wargames much more actively than women and girls (the distribution of genders in this study does not conflict with the Barometer data). These numbers are problematic since all of them are lower than the 3\% margin of error in the study - and since not all people who do miniaturing play games with them. However, the amount of miniature wargamers has stayed relatively constant in the five previous Player Barometers conducted since 2009 (Karvinen \& Mäyrä, 2009, 2011; Kuronen \& Koskimaa, 2010; Mäyrä \& Ermi, 2014; Mäyrä et al., 2016). 


\section{Methods}

This study is a qualitative exploration of miniaturing, a broader pastime that also encompasses miniature wargaming, with the intention of mapping the phenomenon and identifying different facets of it. While it most accurately describes the pastime in Finland, both author experience and previous research (e.g. Carter et al., 2014) suggest that the pastime is similar internationally as well.

The analysis in this paper is based on a data set that was collected in May 2019. An online survey with seven open questions (e.g. "Tell us your miniaturing history?", "Where and when does your miniaturing take place?") and six specific or demographic questions (e.g. age, gender, year when miniaturing started) was distributed through social media (Facebook groups, hobby forums, Twitter). The link to the survey garnered considerable interest; it was shared by key actors in the Finnish miniature wargaming hobby, such as the largest annual convention Ropecon and the biggest hobby store chain Fantasiapelit, as well as being tweeted by prominent people in the community. As a result we received a total of 127 answers. The data set is rich, and it is obvious that many people spent significant effort in filling out the questionnaire. The data corpus from the open questions is 53,000 words long in Finnish, with over 420,000 characters. $7.9 \%(\mathrm{~N}=10)$ of the respondents identified as women, $91.3 \%(\mathrm{~N}=116)$ reported they were men, and $0,8 \%(\mathrm{~N}=1)$ elected not to disclose the information. The ages of the respondents ranged from 18 to 56, with a mean of 35.7 and a median of 35 . As we wanted to focus on adults, the minimum age for participation was 18 .

The range of starting years for miniaturing was very broad, with 1970 being the earliest reported year and 2018 the latest. The median year was 1998. In effect this meant that our respondents were quite experienced, which most likely contributed to the long answers given in the questionnaire. This broad range also gave us some historical perspective into the development of the pastime in Finland. The emphasis on the survey was on capturing a detailed map of the miniature pastime. For that reason we used the emic vernacular in our survey, referring to the activity as figuilu. This Finnish term can be translated as 'engaging with (miniature gaming) figurines'. In this paper we have decided to use the term miniaturing as the English translation of figuilu to communicate the vernacular. 'Figuring', which would be a more direct translation, was deemed too confusing in English.

We conducted a thematic analysis on our data. Thematic analysis is a flexible research method that allows researchers to systematically identify and organize data into patterns of meaning, or themes (Braun \& Clarke, 2012). We conducted our analysis on the semantic level, focusing on what the respondents explicitly reported. We adopted an inductive, exploratory approach as there was scant previous research on miniaturing. In other words, rather than following an established framework or theory, our codes and themes derived from the data (see Braun \& Clarke, 2006, 2012).

The results of the Finnish language questionnaire were coded using the Atlas.ti 8 software. We identified and coded elements in the responses where the participants either described their miniaturing activities and interests (e.g. "My hobby mainly consist of collecting and gaming") or explicitly defined miniaturing or aspects of it (e.g. "A 
miniature is not a toy", "Miniaturing is a way of life"). Similar codes were then combined into broader ones for a final total of 30 codes describing and defining miniaturing. As per the instructions by Braun and Clarke (2006, pp. 19-20), these 30 codes were then sorted and grouped together with similar ones (e.g. "displaying miniatures at home" and "displaying miniatures online" were both interpreted to reflect aspects of a larger whole) to create six broader, overarching themes: gaming, crafting, collecting, storytelling, displaying and appreciating, and socializing. These themes are discussed below in detail.

\section{Results: Miniaturing as a Pastime}

In this section we discuss the results of our study. All the quotes are direct quotes from the data and they have been translated from Finnish by the authors. Obvious typing or spelling errors have not been carried over in the translation. The respondent ID is listed at the end of each quote.

One of the key issues we set out to map, was the shape of miniaturing as a pastime. Earlier research both in Australia (Carter, Gibbs, \& Harrop, 2014) and in Finland (Kankainen, 2016) has shown that even when the focus is on gaming, miniaturing should not be understood simply as gaming. Instead it is a collection of interlinked practices that are better characterized as a pastime or a hobby. As an obvious example, painting miniatures is a key aspect of miniaturing, regardless of whether the miniatures are for gaming purposes or not. Based on the themes we identified in the data, miniaturing activities can roughly be divided into six broad, overlapping categories.

First, there is gaming. Miniatures are often created for the purpose of using them in a game, be it miniature wargames or role-playing games. In both cases the game, its rules and traditions, frame the activity of crafting miniatures. The miniatures are primarily crafted to fit the game, and in the case of wargames, competition is a common element.

For me the most important part of miniaturing is gaming and the development of gaming skills. It's also essential to play face to face, unlike computer games. Painting, making terrain, and putting miniatures together is less important to me. R116

The emphasis is on gaming. Building, converting, painting, and building scenery come with it, but without gaming I wouldn’t do them either. R11

This activity also includes reading and understanding the rules of the games played. Interestingly, gaming can also overlap with storytelling (see below) as players familiarise themselves with the game setting by not just reading the rules, but also consuming transmedially connected media such as novels, films, tv series, and comic books set in the gaming world (see Booth, 2015), whether fictional or historical. In miniature wargames the units are created with specific rules, and the miniatures need to fit the concept and statistics of the unit. This means that part of the preparation for the gaming is drafting specifications for new units and optimizing the usefulness of the unit according to the rules. 
The second category is crafting. We use this term to include all the activities around assembling, painting, making, and modifying miniatures. This goes from painting existing full figurines to combining parts from different miniatures to create a new individual one (typically called "converting"), to sculpting new parts of figurines or even full miniatures. In our data, crafting was most often mentioned as the core of the miniaturing hobby.

The core of miniaturing for me lies in modeling, converting, and painting. After this it's important to get your miniatures onto the battlefield to perform heroics and look great as a whole. $\mathbf{R 2 0}$

Little by little during the years the focus of the hobby shifted clearly more to painting rather than gaming. I do game weekly, but it's mostly using old miniatures and most new miniatures are painted just for fun to put in the display case. R21

Crafting is not necessarily about crafting a miniature figurine, but also extends to creating terrain such as hills or buildings for gaming and displaying purposes as well as creating dioramas and vignettes. In all crafting skills are implied. Our respondents also mentioned trying out new techniques, styles, and approaches in crafting, often picked up from social media, videos, podcasts, and magazines.

The third category is collecting. A majority of our respondents somehow signalled that they had more figurines than they had painted, sometimes even more miniatures that they felt they could ever paint. Collecting miniatures is part of the hobby; it includes browsing catalogues and stores, hunting for old figurines, ordering miniatures online, browsing online flea markets and eBay, and so on. Sometimes our respondents were looking for specific figurines that had left an impression on them at an early age, sometimes they were looking for miniatures for a specific edition of a game or representing a particular aesthetic. The criteria for worthwhile miniatures to purchase varied, but collecting, even hoarding, figurines appears common.

For me miniaturing is primarily collecting. I want good-looking miniatures on the shelf and the gaming table. Buying is a large part of miniaturing. Cleaning up, putting together and basecoating miniatures is a dreary chore that just needs to be done. I have never liked it. R19

Obviously I cannot ignore the fact that I'm a collector by nature. Books, records, comics, apple tree species...little figures suit this frenzy better than well. R97

Fourth, we have storytelling. This is a different kind of crafting endeavour, where people create backstories for the miniatures and units. It is common to think up a specific, possibly even quite detailed, history for a miniature. Sometimes this only manifests in the colours chosen in painting, but it can extend to naming and even writing out full life stories fitting the fictional world. Sometimes miniatures' stories are shaped by the games they participate in - and the scars the fighting leaves can be made visible in the miniature. There is a fair bit of imaginative play and daydreaming happening around 
miniaturing, for example in planning how to physically craft a miniature. However, this play of the imagination is most obvious in the creative creation of life stories for miniatures. While often invisible to others, many respondents reported that this kind of activity is what makes miniaturing special and sets it apart from other activities.

I like making up stories in my mind around the miniatures; I imagine while posing them and when I make bases, I think about the environment they live and do battle in. R12

I'd like for each of my painted miniatures to reflect the personality that I have tried to give them. Especially so-called heroes, miniatures that "lead" the troops or are the most important tokens on the table, are all named. For me I think it's more about pride in my own work than immersion in the game or a created backstory. However, for the small armies that I paint I always make up some kind of a story and background in my mind, because it is not only fun but also provides ideas for the army's paint scheme: are they maybe veterans of a long campaign, with plunder mixed with their dirty gear? Or are they maybe pawns of evil, whose pale skin and clothing colour reflect their alliance with evil? The colour scheme, painting style and the mini's story, "fluff", are all tied together. R72

The fifth broad category is displaying and appreciating. Many of our respondents reported putting up their miniatures for show in glass cabinets and other showcases in their homes. Even more common was taking photographs of the miniatures or dioramas and sharing the images online. Correspondingly, many also reported that they followed not only discussions about the hobby, but specifically photographs and videos of other people's creations, or what has been recognized in earlier research as photoplay (see e.g. Heljakka, 2012). According to the responses, partly this watching is about learning and bettering one's own craft, but there is also a major component of simply appreciating and enjoying the mastery of others' creativity and skill. Displaying also ties into interactions with non-miniature enthusiasts: according to the respondents, even people who are not otherwise interested in miniatures, such as friends, co-workers and family members, often appreciate seeing painted miniatures and comment on the skill involved.

I often share my end results in FB groups, because it's nice to get compliments. Not so much on the painting, but more on the clever conversions. R5

I look at other people's miniatures on Insta[gram] every day and find inspiration and ideas for my own work as well. R10

Miniatures are obviously photographed, and often the working phases as well. I browse a lot of other people's versions of my miniatures before putting them together and painting them. It's sometimes a little demotivating as the web is full of very talented individuals, but even more I get excited when I discover cool ideas. R19

The sixth category is socializing around miniaturing. While much of the crafting was done as a solitary pursuit, many respondents reported that getting together with 
their friends for gaming was the best part of the miniaturing pastime for them. Socializing was not limited to gaming, as other reported social activities included painting miniatures socially, traveling to events together with fellow hobbyists and running gaming clubs. Crafting aspects of miniaturing were sometimes done in the same space with other family members.

In gaming I appreciate the social interaction and friendships made through it. [...] Painting is usually done alone, but I share the process both live and digitally with family, friends and a broader social media community. The social portion is an important part of my current hobby. R21

Miniaturing for me is very social. I game with by brother, my circle of friends and strangers. I've also found new friend groups through gaming. I don't hide my miniaturing geek culture is pop nowadays. R116

There is considerable overlap with the categories. Based on our data, a typical example of the wargaming hobby has several overlaps such as gaming and collecting (collecting particular miniatures or armies explicitly for gaming purposes), gaming and socializing (playing miniature games together with friends) and crafting and socializing (social painting or scenery building sessions). As another example, sharing photos of painted miniatures in online communities is an activity with elements of crafting (in the form of painting and photography), displaying and appreciating and socializing (in the form of sharing photos and discussing them in online communities).

The results highlight the nature of miniaturing as a collection of different elements. These elements can be analytically separated, but in actual practice they bleed into each other. However, these categories clearly show a multitude of ways of engaging with miniatures, sometimes starkly contrasting with each other. As an example, an almost polar difference exists between miniaturists who collect out of production miniatures for painting and displaying purposes, and role-playing game enthusiasts who use miniatures to illustrate tactical combat situations in games. In the former, miniatures are approached as display items, valuable collectibles, and sometimes works of art, whereas in the latter the role of miniatures is very much functional: they are first and foremost gaming pieces, visually interesting pawns.

Indeed, according to our respondents, while there are numerous ways to engage with miniatures, two approaches are more central than others. This is the dual core to miniaturing: Many reported miniature gaming as the most important part of the hobby, but it was even more common to see the crafting of the miniatures as the core. While gaming may frame the hobby - be it miniature wargaming or role-playing games - for most of the respondents the time spent playing was much lower than the time spent on preparing to play or other miniature-related pursuits. To illustrate, many reported that their focus had shifted from the anticipation of play to enjoying the crafting of the miniatures. Some had even stopped playing altogether or had played very seldom in the first place. 
I play with miniatures quite seldom nowadays, only a few times a year. Once finished, they go in the display case, direct to storage or some as gifts. Miniaturing also ties in with a general history hobby, on the gaming side I'm nowadays more of a theoretician and a rules collector (I have something like two hundred plus rulesets) than a gamer as such. R32

This means that the dual core of miniaturing is object play (crafting, imagining) and social play (gaming, displaying) (see Burghardt, 2005). The pastime cannot be reduced to either one of these, both are central.

\section{Situating Miniaturing}

Our rich data corpus and analysis reveals a wide variety of ways people engage with miniatures. Our respondents contextualized miniaturing in numerous different ways. Miniaturing is a hobby, it is crafting, it is playing, and it is gaming. Nowadays there is also an important element of sharing on social networks online.

In this article we have opted to discuss miniaturing primarily with the neutral term 'pastime'. Clearly, playing and games are traditionally thought of as (occasional) activities of leisure and could therefore be seen as pastimes. As a pastime, playing with miniatures may take either toy-play or game-play like forms. In line with Carter, Gibbs, and Harrop (2014), who described the miniature game WARHAMMER 40,000 as a playful pastime, our results suggest that the description is appropriate for miniaturing, i.e. engagement with miniatures, more broadly as well.

Miniature-related activities are plural, making the situating of miniaturing difficult. As the pastime is heterogeneous, it cannot neatly be placed in any one context. Miniaturing is a family of interlinked practices, with a dual core of gaming and crafting, that different individuals engage in according to both their preferences as well as situational variables such as the availability of time, money, or social connections. Furthermore, there are a number of contentious areas. It is, for example, common to describe miniaturing as both a social and a solitary activity, memorable gaming nights with friends contrasting with solitary painting sessions, repeatedly described as "meditative" or "therapeutic". The miniatures themselves are seen as game pieces, implements of play, collectibles, decorative items, and a medium of self-expression. Interestingly, our respondents characterize them as both toys and not-toys, the latter view being more common.

The social side is a big part of my enjoyment of gaming, but putting miniatures together and painting is primarily my private hobby that I have at times shared with my companion and on some occasions also with my children. $\mathbf{R 2 3}$

Gaming is play. But miniatures are not toys. $\mathbf{R 3 8}$

I guess after all it's a certain type of play. Playing is a lifelong process, the toys just become nicer. Motorcycles and the like are toys as well. R34. 
Toys are often defined solely as objects related to childhood, not as playthings for all ages (Heljakka, 2013), marking both the toy objects and play as unfitting, even shameful for adults. Toy play, as a type of object play (see Smith, 2010), has been traditionally associated with children's use of various physical materials in their play. Nevertheless, there is evidence that mature players engage in various ways with physical objects meant for playing purposes, such as dolls, action figures and figurines. This play that includes personalization, role-play and aspects of storytelling can be understood both as world-building, as well as world-play (Heljakka \& Harviainen, 2019).

Just as there is tension between toys and not-toys, there is tension between the framings of 'gaming' and 'playing'. Many respondents reported playing, in contrast to gaming, with miniatures. This took different forms such as imagining, making up stories, setting up miniatures for photography, and generally adapting a playful state of mind (see Heljakka, 2013, 2018; Stenros, 2015) when engaging with miniatures. On the other hand, some respondents stressed that they were gaming, not playing, and this framing was connected to seeing miniatures as game pieces, not toys. The element of competition was present in some of these responses, suggesting a traditional distinction between ludus, or structured, rule-constrained play, and paidia, or playful and more free-form play (Caillois, 2001). Some respondents mentioned using miniatures to play with their children, sometimes with the hope of getting their children interested in miniatures in general.

This friction between toys and not-toys as well as games and play is particularly interesting, as it has a long history. Wargaming has been conducted with 'toy soldiers', yet done by adults engaged in a serious pursuit. These tensions perhaps tell us more about the societal framing and acceptance of adult play (see e.g. Heljakka, 2016; Riezler, 1941), than about wargaming or miniaturing, but it continues to frame the way miniaturing is thought of and talked about to this day. Some respondents mentioned not discussing their miniaturing publicly for fear of mockery especially when they were younger. A few respondents reported currently keeping their miniaturing mostly private, but motives for this varied. Many respondents mentioned situations in which they had received compliments and praise from non-miniaturists. Interestingly one respondent specifically made a distinction between their miniaturing hobby and their toy hobby, with the former being highly social and the latter much more private.

It is noteworthy, that while gaming featured prominently in our data, our respondents did not position their miniaturing pastime as a continuation of a centuries long practice of wargaming. Instead, and perhaps unsurprisingly, our respondents situated themselves in relation to the post-role-playing game phase of miniature wargaming, where fantasy is a key component. Imaginative play in a coherent fantasy story-world (see Saler, 2012) appears to be an important ingredient in the pastime. This brings miniaturing, for many participants, closer to world-building, storytelling, and fan practices such as fan fiction. Indeed, perhaps the separation of playing with toys from the playing of games is not useful, since these practices exist on a continuum (cf. Burghardt, 2005). Rules emerge in free-form play and rule-based game play interlinks with creative endeavors. Miniaturing can be argued to resemble world-building or world-play that includes aspects of toy-play and game-play (see Heljakka \& 
Harviainen, 2019), as well as transmedia-based play patterns inspired by other media products (see Booth, 2015).

The strong prominence of crafting elements in miniaturing is an important result. The practice of converting (i.e. customizing) miniatures clearly resembles customization of character toys, such as dolls or action figures. A trend connecting with the doit-yourself (DIY) and maker cultures, the customization and personalisation of toys represents an important direction of creative play practices over the past years (see Godwin, 2015; Heljakka, 2016). Many players want to personalise their dolls through physical interventions, such as modifying facial features through painting or changing the hairdo by 're-rooting' hair. Toys are in this way given a new, individual, and customised appearance as a result of the player's handicraft. Consequently, creative manipulation of toys may build a player's, or a miniature enthusiast's, crafting skills (see e.g. Heljakka, 2015; Hills, 2010). Customizing miniatures can also be seen as an expression of mimetic fandom (Hills, 2010) with both transformative elements, such as when a miniaturist creates a novel physical rendition of a character described in fiction or reinterprets an existing model or character, and affirmative elements, such as accurately replicating historical or fictional uniforms and gear or painstakingly reproducing a piece of two-dimensional artwork with miniatures (see Godwin, 2015).

In our data, the most common way of talking about miniaturing in a broad fashion was as a 'hobby'. This connects miniaturing activities with similar endeavours of organized 'toy-enthusiasts'. For example, people involved in toy-related associations do not typically address their activity with toys as play, or even as necessarily collecting, but as a hobby (Heljakka, 2016). Hobbying comes out as a more structured and goal-driven form of leisure. The Industrial Revolution made way to leisure time and in this way opened a larger space in Western life for hobbies, "the work-like play" (Maines, 2009). When hobbying with miniatures, the respondents of our study showed a tendency to have articulated aims in relation to their specific activities. These goals connected, for example, to the painting of miniatures or competitive gaming.

Finally, the element of collecting, even hoarding, is so widespread in miniaturing, that it cannot be ignored. This observation finds purchase in previous literature on fandom and toy collecting, in which it has been argued that not only can collecting in itself be a creative act (Hills, 2009) or an expression of playfulness (Heljakka, 2017), but that an individual's collection identifies their level of fandom (Geraghty, 2014) and defines their qualities as a player (Heljakka, 2017). It is apparent from our data, that the reasons for accumulating miniatures go not only beyond simple utilitarian uses, but also more complex goals determined by collecting or hoarding. According to our data, miniatures have value as commercial products, collectibles, game character representations, and even as pieces of art. For some respondents, the cost of miniatures was prohibitive and limited their participation in the activity, whereas others had hundreds, if not thousands, of unpainted miniatures, which they assumed they might never get around to painting. A deeper analysis of this dimension of the pastime, i.e. collecting and consumer behaviour, will be presented in a future article. 


\section{Conclusions}

The data presented in this paper illustrates how miniaturing is a multifaceted activity with a dual core. Gaming with miniatures and crafting new ready figurines, scenery, and dioramas are central to miniaturing, but collecting, storytelling, socializing as well as displaying and appreciating are also important parts of the pastime. The pastime can be situated and framed in numerous fashions: for example as gaming, as playing, as toying, and as crafting. None of these framings apply to all of our respondents, but all of them are relevant to some subsection. Some of them are actively contested, such as viewing miniaturing as playing with toys, but even the contested approaches seem like fertile angles of approach in future research.

The findings are based on Finnish qualitative data. This, as well as the self-selected sample, needs to be minded when considering the generalizability of the results. Nevertheless, based on previous research, personal experience and numerous discussions with miniature enthusiasts from both Finland and other countries, we believe that our study is an accurate, if limited, exploration of miniaturing. By examining the various aspects of miniaturing and situating them in relation to concepts such as play, game, and hobby, our study lays essential groundwork for further exploration of both our data and the broader phenomenon.

\section{Declaration of Conflicting Interests}

The authors declared no potential conflicts of interest with respect to the research, authorship, and/or publication of this article.

\section{Funding}

This research is funded in part by the Academy of Finland Centre of Excellence in Game Culture Studies (CoE-GameCult, grant \#312395) and the Academy of Finland Strategic Research Council project Growing Mind: Educational transformations for facilitating sustainable personal, social, and institutional renewal in the digital age (grant \#322603).

\section{ORCID iD}

Mikko Meriläinen (iD https://orcid.org/0000-0001-9621-684X

\section{References}

Booth, P. (2015). Game play: Paratextuality in contemporary board games. Bloomsbury Academic.

Braun, V., \& Clarke, V. (2006). Using thematic analysis in psychology. Qualitative Research in Psychology, 3(2), 77-101.

Braun, V., \& Clarke, V. (2012). Thematic analysis. In H. Cooper, P. M. Camic, D. L. Long, A. T. Panter, D. Rindskopf, \& K. J. Sher (Eds.), APA handbook of research methods in psychology, Vol. 2. Research designs: Quantitative, qualitative, neuropsychological, and biological (pp. 57-71). American Psychological Association.

Burghardt, G. M. (2005). The genesis of animal play. Testing the limits. The MIT Press.

Caillois, R. (2001). Man, play and games (M. Barash, Trans.). University of Illinois Press. (Original work published 1958, original English translation 1961). 
Carter, M., Gibbs, M., \& Harrop, M. (2014). Drafting an army: The playful pastime of Warhammer 40,000. Games and Culture, 9(2), 122-147. https://doi.org/10.1177/1555412013513349

Carter, M., Harrop, M., \& Gibbs, M. (2014). The roll of the dice in Warhammer 40,000. In F. Mäyrä, . Heljakka, \& A. Seisto (Eds.), ToDIGRA. Physical and digital in games and play (pp. 1-28). ETC Press. https://doi.org/10.26503/todigra.v1i3.20

Clerc, L. (2018). Lohikäärmeen luolassa. Fantasiapelit Tudeer Oy 1980-luvulta 2010-luvulle [In the dragon's den. Fantasiapelit Tudeer Ltd. from the 1980s to the 2010s]. In J. Stenros \& J. Särkijärvi (Eds.), Seikkailuja ja sankareita. Katsaus suomalaisen roolipelaamisen historiaan ja nykyhetkeen [Adventures and heroes. A look at the history and the present of Finnish role-playing] (pp. 47-62). Tampereen museoiden julkaisuja 153.

Cova, B., Pace, S., \& Park, D. J. (2007). Global brand communities across borders: The Warhammer case. International Marketing Review, 24(3), 313-329. https://doi.org/ $10.1108 / 02651330710755311$

Dunnigan, J. F. (2005). The complete wargames handbook. http://www.professionalwargaming.co.uk/Complete-Wargames-Handbook-Dunnigan.pdf

Games Workshop. (2019). Annual report 2019. https://investor.games-workshop.com/wp-con tent/uploads/2019/07/2018-19-Annual-Report-with-Cover.pdf

Geraghty, L. (2014). Cult collectors: Nostalgia, fandom and collecting popular culture. Routledge.

Godwin, V. (2015). Mimetic fandom and one-sixth-scale action figures. Transformative Works and Cultures, 20. https://doi.org/10.3983/twc.2015.0686

Harrop, M., Gibbs, M., \& Carter, M. (2013). Everyone's a winner at Warhammer 40K (or, at least not a loser) [Conference session]. DiGRA 2013 Conference: DeFragging Game Studies, 26-29 August, Atlanta, GA.

Heljakka, K. (2012). Aren't you a doll! Toying with avatars in digital playgrounds. Journal of Gaming \& Virtual Worlds, 4(2), 153-170. https://doi.org/10.1386/jgvw.4.2.153_1

Heljakka, K. (2013). Principles of adult play(fulness) in contemporary toy cultures: From wow to flow to glow (Aalto University publication series DOCTORAL DISSERTATIONS 72/2013). Aalto ARTS Books.

Heljakka, K. (2015). Toys as tools for skill-building and creativity in adult life. Seminar.net, 11(2), 134-148.

Heljakka, K. (2016). More than collectors: Exploring theorists', hobbyists' and everyday players' rhetoric in adult play with character toys. Games and Culture, 13(3), 240-259. https:// doi.org/10.1177/1555412016670493

Heljakka, K. (2017). Toy fandom, adulthood, and the ludic age. In J. Gray, C. Sandvoss, \& C. L. Harrington (Eds.), Fandom: Identities and communities in a mediated world (2nd ed., pp. 91-105). New York University Press.

Heljakka, K., \& Harviainen, J. T. (2019). From displays and dioramas to doll dramas. Adult world building and world playing with toys. American Journal of Play, 11(3), 351-378.

Hills, M. (2009). "Interview with Dr. Matt Hills part 2"” on doctorwhotoys.net website. http:// doctorwhotoys.net/matthills1.htm

Hills, M. (2010, September 10). As seen on screen? Mimetic SF fandom and the crafting of replica(nt)s. In Media Res. http://mediacommons.futureofthebook.org/imr/2010/09/10/ seen-screen-mimetic-sf-fandom-crafting-replicants

Kankainen, V. (2016). The interplay of two worlds in Blood Bowl: Implications for hybrid board game design [Conference session]. 13th International Conference on Advances in Computer Entertainment Technology, Article No. 8. ACM. https://doi.org/10.1145/3001773.3001796 
Karvinen, J., \& Mäyrä, F. (2009). Pelaajabarometri 2009. Pelaaminen Suomessa [Player barometer 2009. Game play in Finland]. Interaktiivisen median tutkimuksia 3. University of Tampere. http://www.pelisaatio.fi/wp-content/uploads/2012/12/Pelaajabarometri_2009. pdf

Karvinen, J., \& Mäyrä, F. (2011). Pelaajabarometri 2011. Pelaamisen muutos [Player barometer 2011. Changing game play] (TRIM Research Reports 6). University of Tampere. https://trepo.tuni.fi/bitstream/handle/10024/65502/pelaajabarometri_2011.pdf

Kinnunen, J., Lilja, P., \& Mäyrä, F. (2018). Pelaajabarometri 2018. Monimuotoistuva mobiilipelaaminen [Player barometer 2018. Diversifying mobile gaming] (TRIM Research Reports 28). University of Tampere. http://urn.fi/URN:ISBN:978-952-03-0870-4

Kunttu, T. (2018). Navy game. Object of the month - October 2018. The National Museum of Finland. https://www.kansallismuseo.fi/en/items-of-the-month/2018/laivastopeli

Kuronen,E., \& Koskimaa, R.(2010). Pelaajabarometri 2010 [Player barometer 2010]. Jyväskylän yliopisto. https://jyx.jyu.fi/bitstream/handle/123456789/47368/978-951-39-4236-6.pdf

Lewin, C. G. (2012). War games and their history. Fonthill.

Maines, R. P. (2009). Hedonizing technologies. Paths to pleasure in hobbies and leisure. The Johns Hopkins University Press.

Mäyrä, F., \& Ermi, L. (2014). Pelaajabarometri 2013. Mobiilipelaamisen nousu [Player barometer 2013. The rise of mobile gaming] (TRIM Research Reports 11). http://urn.fi/URN:I SBN:978-951-44-9425-3

Mäyrä, F., Karvinen, J., \& Ermi, L. (2016). Pelaajabarometri 2015. Lajityyppien suosio [Player barometer 2015. Genre popularity] (TRIM Research Reports 21). University of Tampere. https://trepo.tuni.fi/bitstream/han dle/10024/99003/978-952-03-0153-8.pdf

Murray, H. J. R. (1952). A history of board-games other than chess. Clarendon Press.

Peterson, J. (2012). Playing at the world. A history of simulating wars, people and fantastic adventures from chess to role-playing games. Unreason Press.

Peterson, J. (2018). Precursors. In J. P. Zagal \& S. Deterding (Eds.), Role-playing game studies: Transmedia foundations (pp. 55-62). Routledge.

Riezler, K. (1941). Play and seriousness. Journal of Philosophy, 38(19), 505-517. https://doi .org/10.2307/2017298

Saler, M. (2012). As if: Modern enchantment and the literary prehistory of virtual reality. Oxford University Press.

Schuurman, P. (2017). Models of war 1770-1830: The birth of wargames and the trade-off between realism and simplicity. History of European Ideas, 43(5), 442-455. https://doi.org /10.1080/01916599.2017.1366928

Smith, P. K. (2010). Children and play: Understanding children's worlds. John Wiley \& Sons.

Stenros, J. (2015.). Playfulness, play, and games: A constructionist ludology approach (Acta Universitatis Tamperensis 2049). Tampere University Press.

Suomen pelimuseo. (n.d.). 100 suomalaista peliä. Listing of the 100 games featured in the museum. http://vapriikki.fi/pelimuseo/pelit/

\section{Author Biographies}

Mikko Meriläinen $(\mathrm{PhD})$ is a postdoctoral researcher at Tampere University Game Research Lab, working in the "Growing Mind: Educational transformations for facilitating sustainable personal, social, and institutional renewal in the digital age" research project. In his work he focuses on questions of youth gaming cultures, gaming-related parenting and game jam learning.

Contact: mikko.merilainen@tuni.fi 
Jaakko Stenros $(\mathrm{PhD})$ is a University Lecturer in Game Studies working at the Centre of Excellence in Game Culture Studies at the Game Research Lab, Tampere University. He has published nine books and over 50 articles and reports and has taught game studies for a decade. Stenros has also collaborated with artists and designers to create ludic experiences and has curated many exhibitions at the Finnish Museum of Games.

Contact: jaakko.stenros@tuni.fi

Katriina Heljakka, Doctor of Arts, is a researcher at Pori Laboratory of Play, University of Turku (digital culture studies). Her background is in toy research with a particular interest in adult toy play and character toys. Heljakka currently studies connected toys, playful tools, techniques and environments in the workspace, and the visual, material, digital and social cultures of play. Her main interests include the emerging toyification of culture, toy design, playful spaces and the hybrid and transgenerational dimensions of ludic practices.

Contact: katriina.heljakka@utu.fi 